\title{
In vitro profiling of the endocrine disrupting potency of organochlorine pesticides
}

\author{
Jian $\mathrm{Li}^{\mathrm{a}}$, Na Li ${ }^{\mathrm{a}}$, Mei Ma ${ }^{\mathrm{a}}$, John P. Giesy ${ }^{\mathrm{b}, \mathrm{c}, \mathrm{d}}$, Zijian Wang ${ }^{\mathrm{a}, *}$ \\ a State Key Laboratory of Environmental Aquatic Chemistry, Research Center for Eco-Environmental Sciences, Chinese Academy of Sciences, \\ P.O. Box 2871, Beijing 100085, China \\ ${ }^{\mathrm{b}}$ Department of Veterinary Biomedical Sciences and Toxicology Center, University of Saskatchewan, Saskatoon SK S7N 5B3, Canada \\ c Zoology Department, Center for Integrative Toxicology, National Food Safety and Toxicology Center, Michigan State University, East Lansing, MI 48824, USA \\ ${ }^{\mathrm{d}}$ Department of Biology and Chemistry, Research Centre for Coastal Pollution and Conservation, City University of Hong Kong, 83 Tat Chee Avenue, Kowloon, Hong Kong
}

\section{A R T I C L E I N F O}

\section{Article history:}

Received 29 May 2008

Received in revised form

21 September 2008

Accepted 2 October 2008

Available online 17 October 2008

\section{Keywords:}

Organochlorine pesticides

Estrogen receptor

Androgen receptor

Progesterone receptor

Estrogen-related receptor

Endocrine disruptor

\begin{abstract}
A B S T R A C $T$
Some organochlorine pesticides (OCPs) are suspected of modulating the endocrine systems of humans. Aspects of neuro-endocrine system modulation include interactions such as agonism or antagonism of estrogen receptor (ER) binding. However, less is known about their interactions with other nuclear receptors (NRs). The objectives of this study were to determine and compare the ability of $p, p$ 'dichlorodiphenylethane ( $p, p^{\prime}$-DDE), $p, p^{\prime}$-dichlorodiphenyltrichloroethane ( $p, p^{\prime}$-DDT), hexachlorobenzene (HCB) and $r$-hexachlorocyclohexane $(r-\mathrm{HCH})$ to interact with ER $\alpha$, androgen receptor (AR), progesterone receptor (PR) and estrogen-related receptor (ERR $\gamma)$ using a set of recombined yeast strains expressing $\beta$ galactosidase, under control of $\mathrm{ER} \alpha, \mathrm{AR}, \mathrm{PR}$ or ERR $\gamma$. The results showed that $p, p^{\prime}-\mathrm{DDE}$ was an ER $\alpha$ agonist, AR and PR antagonist (PR > AR), while p, p'-DDT was an ER $\alpha$ agonist and AR antagonist. HCB and $r$-HCH were antagonists for AR and ERR $\gamma$, while $r$-HCH was a PR antagonist and a weak antagonist of ERR $\gamma$, and was able to reverse the ERR $\gamma$ inhibition induced by 4-hydroxytamoxifen. All the results suggested that, for the tested OCPs, their ability to act as endocrine disruptors involves more than one mechanism, their (anti-)agonistic effects on different receptors should not be overlooked, and the potential for additive or synergistic effects must be taken into consideration in the risk assessment process.
\end{abstract}

(c) 2008 Elsevier Ireland Ltd. All rights reserved.

\section{Introduction}

Over the past 20 years there has been increasing concern by both the public and researchers that pesticides and many other environmental chemicals possess the ability to modulate the neuro-endocrine system and thus adversely affect human and wildlife reproduction (Colborn et al., 1993), including direct hormone agonists or antagonists that could mimic or inhibit endogenous hormone action, modulate the production of endogenous hormones, or alter hormone receptors (Sonnenschein and Soto, 1998). Hormone receptors have become one of the subjects of research on endocrine disruptors in general, but much of the research has focused primarily on estrogen receptor (ER) agonists. However, the endocrine system is more complex and presents a large number of potential endocrine disrupting chemical (EDC) tar-

\footnotetext{
* Corresponding author at: State Key Laboratory of Environmental Aquatic Chemistry, Research Center for Eco-Environmental Sciences, Shuangqing Road 18, Haidian District, Beijing 100085, China. Tel.: +86 10 62849140; fax: +86 1062849140.

E-mail address: wangzj@rcees.ac.cn (Z. Wang).
}

get sites (Kristensen et al., 2006). Thus, to accurately predict the potential effects of endocrine disruptors, it is important to study the interaction of EDCs with more hormone receptors.

The steroid receptors, including the ERs, androgen receptors (ARs) and progesterone receptors (PRs) are classified as members of the subfamily within the nuclear receptor super-family 3 (Nuclear Receptors Nomenclature Committee, 1999). It is well known that androgens are important physiologically in male mammals by regulating many functions in development such as prostate growth and the maintenance of prostatic function, and so on (Meisel and Sachs, 1994). Recent studies have shown that several chemicals may exert anti-androgenic effects by interfering with AR, such as $p, p^{\prime}-$ dichlorodiphenylethane ( $\left.p, p^{\prime}-\mathrm{DDE}\right)$, bisphenol A and nonylphenol (Sohoni and Sumpter, 1998; Xu et al., 2005).

Besides estrogens and androgens, progesterone is also a key regulator of proliferation and differentiation in reproductive tissues (Graham and Clarke, 1997). The effects of progesterone are mediated via the PR. Several pieces of evidence indicate that some environmental samples (e.g., soot from fossil fuel combustion) are able to inhibit the binding of the progesterone to PR (Wang et al., 2005). But only a limited number of environmental chemicals with 
anti-progesterone-like properties have been identified (Klotz et al., 1997).

Because no endogenous ligands have been identified for the estrogen-related receptors (ERRs), they are classified as a subfamily of orphan nuclear receptors. ERRs and ERs have a high degree of amino acid sequence similarity and identity in both their DNA-binding (DBD) and ligand-binding (LBD) domains (Horard and Vanacker, 2003). ERRs can bind to functional estrogen response elements (EREs) in ER target genes, suggesting possible similarities between ERR and ER action (Takayanagi et al., 2006). Some synthetic chemicals including bisphenol A, diethylstilbestrol, 4nonylphenol and some phytoestrogens have been reported to be able to bind to human ERR $\gamma$, one member of ERR family (Takayanagi et al., 2006).

Even though most OCPs have been banned for decades, they are still highly persistent in the environment, it has been reported that fish that are stocked into contaminated lakes fail to reproduce raising the possibility that exposure to OCPs has impaired their endocrine systems (Johnson, 1999). p,p'-DDE and $p, p^{\prime}$-dichlorodiphenyltrichloroethane ( $p, p^{\prime}$-DDT) have been long acknowledged to be estrogenic chemicals having the ability to interact with human ER $\alpha$ (Soto et al., 1995; Chen et al., 1997), and $p, p$ '-DDE recently has been reported to act as an antagonist for a human AR (Kelce and Wilson, 1997). However, this study was not conducted to determine the effects of these specific OCPs on other nuclear receptors, but rather to obtain additional information by providing a comprehensive steroid receptor profile of OCPs. For this purpose, the recombinant yeast assays were carried out to investigate the effects of $p, p^{\prime}-\mathrm{DDE}, p, p^{\prime}$-DDT, hexachlorobenzene (HCB) and $r$-hexachlorocyclohexane $(r-\mathrm{HCH})$ on ER $\alpha, \mathrm{AR}, \mathrm{PR}$ and ERR $\gamma$-mediated transcription of $\beta$-galactosidase in vitro in reporter yeasts.

\section{Materials and methods}

\subsection{Chemicals}

$17 \beta$-Estradiol $\left(\mathrm{E}_{2}, 97 \%\right)$, dimethyl sulfoxide (DMSO, 99.5\%), p,p'-DDE (99.6\%), HCB (99\%), p,p'-DDT (99\%), $r$-HCH (99\%), and 4-hydroxytamoxifen (4-OHT, 98\%) were purchased from Sigma Chemical (St. Louis, MO, USA). Dihydrotestosterone (DHT) was obtained from TCI (Osaka, Japan). Progesterone was purchased from the MP Biomedical, Eschwege, Germany. RU486 was purchase form the Beijing Zizhu Pharmaceutical, Beijing, China. Hydroxyflutamide was purchased from the Toronto Research Chemicals, North York, Canada. For all compounds, stock solutions were prepared in DMSO. Final chemical concentration in the DMSO stock was $0.2 \mathrm{~mol} / \mathrm{L}$.

\subsection{Plasmids}

The yeast expression plasmids, pGBT9 ERR $\gamma$ and pGAD424 GRIP1/FL, were kindly provided by Michael R. Stallcup at the Department of Biochemistry and Molecular Biology, University of Southern California (San Diego, CA, USA). The pGBT9 ERR plasmid, coding for fusion proteins of GAL4 DNA-binding domain and the ligandbinding domain of the ERR $\gamma$, was constructed as described previously (Hong et al., 1999). Another plasmid, pGAD424 GRIP1/FL, coding for fusion proteins of GAL4 DNA-activation domain and full-length GRIP1/FL was reported by Hong et al. (1997). The third plasmid, coding for fusion proteins of GAL4 DNA-binding domain and the ligand-binding domain of AR, called pGBT9 AR, was kindly provided by J. Trapman at the Department of Pathology, Erasmus University Medical Centre (Rotterdam, Holland) and described by Doesburg et al. (1997). All sequences of plasmids were confirmed by DNA sequencing.

\subsection{Yeast strain}

The yeast strain used in the two-hybrid system was Y187 obtained from Clontech (Palo Alto, CA, USA). Yeast cells were co-transformed with the pGBT9 ERR $\gamma$ and pGAD424 GRIP1/FL or pGBT9 AR and pGAD424 GRIP1/FL using a lithium acetate method and selected by growth on synthetic dextrose (SD) medium (lacking tryptophan and leucine, SD/-Leu/-Trp) added agar according to Clontech yeast protocols handbook.

We constructed a two-hybrid yeast strain containing ER $\alpha$ and coactivator sequences, which were maintained in SD/-Leu/-Trp (Li et al., 2008). The yeast strain transformed with the PR gene was a kind gift of Dr. Kevin W. Gaido (Chemical
Industry Institute of Toxicology, Research Triangle Park, North Carolina, USA). Yeast (Saccharomyces cerevisiae) stably transfected with the human PR gene and expression plasmids carrying a progesterone response element, while the reporter LacZ gene encoding the enzyme $\beta$-galactosidase was used. The yeast strain was grown in synthetic complete (SC) medium with tryptophane, but lacking histidine and leucine (SC/-His/-Leu) following the prescription of Gaido et al. (1997).

\section{4. $\beta$-Galactosidase assay}

The yeast assay was conducted as described by Ma et al. (2005). Yeast strains were grown overnight at $30^{\circ} \mathrm{C}, 130 \mathrm{rpm}$ with vigorous shaking. Each test chemical was serially diluted in DMSO. Five microliters of serial dilutions of test samples were combined with $995 \mu \mathrm{L}$ of medium containing $5 \times 10^{3}$ yeast cells $/ \mathrm{mL}$ resulting in a test culture. Two hundred microliters of the test cultures were transferred into each well of the 96 -well plate and incubated at $30^{\circ} \mathrm{C}$ with vigorous orbital shaking $(800 \mathrm{rpm})$ for $2 \mathrm{~h}$, then the cell density of the culture was measured at $600 \mathrm{~nm}$ wavelength (TECAN GENios A-5002, Salzburg, Austria).

A $50 \mu \mathrm{L}$ test culture was transferred to a new 96 -well plate and after addition of $120 \mu \mathrm{L}$ of Z-buffer $\left(16.1 \mathrm{~g} / \mathrm{L} \mathrm{Na}_{2} \mathrm{HPO}_{4} \cdot 7 \mathrm{H}_{2} \mathrm{O} ; 5.5 \mathrm{~g} / \mathrm{L} \mathrm{NaH} \mathrm{PO}_{4} \cdot \mathrm{H}_{2} \mathrm{O} ; 0.75 \mathrm{~g} / \mathrm{L}\right.$ $\mathrm{KCl} ; 0.246 \mathrm{~g} / \mathrm{L} \mathrm{MgSO}_{4} \cdot 7 \mathrm{H}_{2} \mathrm{O}$ ) and $20 \mu \mathrm{L}$ chloroform, the assays were carefully mixed (vortex $25 \mathrm{~s}$ ). The enzyme reaction was initiated by addition of $40 \mu \mathrm{L} o$-nitrophenyl$\beta$-D-galactopyranoside $\left(13.3 \mathrm{mmol} / \mathrm{L}\right.$, dissolved in Z-buffer) and incubated at $30^{\circ} \mathrm{C}$ for $60 \mathrm{~min}$. The reactions were terminated by the addition of $100 \mu \mathrm{L} \mathrm{Na}_{2} \mathrm{CO}_{3}$ $(1 \mathrm{~mol} / \mathrm{L}$ ). After centrifugation at $12,000 \mathrm{~g}$ for $15 \mathrm{~min}$ (Sigma Laborzentrifugen $2 \mathrm{~K} 15$ Osterode, Germany), $200 \mu \mathrm{L}$ of the supernatant was transferred into a new 96-well plate and the absorbance at $420 \mathrm{~nm}$ was determined. The $\beta$-galactosidase activity was calculated according to reports by Ma et al. (2005), $\beta$-galactosidase activities are expressed as the means and standard deviations of the results from three independent transformed yeast clones and for each clone, all samples were evaluated in triplicate. The antagonistic activity of samples was tested by co-incubation of yeast strain with natural ligand which produced a sub-maximal stimulatory response (Wang et al., 2005).

To ensure that increased/reduced activities in the bioassay were caused by true agonistic/antagonistic responses and not by cytotoxicity, viability was measured After exposure, cell viability was determined spectrophotometrically as a change of cell density $\left(\mathrm{OD}_{600} \mathrm{~nm}\right)$ in the assay medium.

\subsection{Data analysis}

For known agonists or antagonists, the concentration inducting $50 \%$ of control (REC50) or the concentration inhibiting $50 \%$ of control (RIC50) was calculated. Some test compounds, at the concentrations used, did not produce an effect as great as 50\% of control. Therefore, potency was compared using the concentration that induced an effect $20 \%$ of control. Thus, for agonists a $20 \%$ relative effect concentration (REC20) was calculated, and for antagonists a $20 \%$ relative inhibitory concentration (RIC20) was calculated. Where the effect of the highest concentration tested was less than $20 \%$ different from positive control, but significantly different from negative control, the REC20 or RIC20 is shown in Table 1 as being greater than the highest concentration tested. The dose-response curve was generated using a four-parameter logistic model based on the Marquardt-Levenberg algorithm (Sigmaplot 4.0, SPSS Chicago, IL, USA) (Rehmann et al., 1999).The four-parameter logistic equation gives a dose-response curve fitted to the measured values REC20 as well as the opportunity to calculate RIC20 values for antagonistic assays.

\section{Results and discussion}

\subsection{Response to known agonists and antagonists}

The reporter assay system showed appropriate responses to DHT and progesterone which are known AR and PR agonists, respectively. These chemicals induced $\beta$-galactosidase activity in a concentration-dependent manner in the test concentrations (Fig. 1). Maximal induction of DHT was caused by $5 \times 10^{-6} \mathrm{~mol} / \mathrm{L}$, with a REC50 of $1.3 \times 10^{-8} \mathrm{~mol} / \mathrm{L}$. Maximal induction by progesterone was caused by $1 \times 10^{-8} \mathrm{~mol} / \mathrm{L}$, and the REC50 was $5 \times 10^{-10} \mathrm{~mol} / \mathrm{L}$. Because the specific agonist of ERR $\gamma$ has not been found, induction activity was not tested.

To characterize the response of the assay system to AR antagonists, the known AR antagonist hydroxyflutamide was co-administered with $5 \times 10^{-8} \mathrm{~mol} / \mathrm{L}$ of DHT which produced a sub-maximal response. Hydroxyflutamide significantly inhibited $\beta$-galactosidase activity induced by DHT at concentration of $1 \times 10^{-9} \mathrm{~mol} / \mathrm{L}$ and greater (Fig. 2A). The RIC50 for hydroxyflutamide was $8.2 \times 10^{-8} \mathrm{~mol} / \mathrm{L}$. Similarly, the inhibition activity 
Table 1

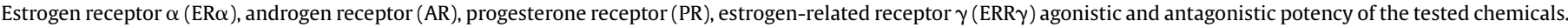

\begin{tabular}{|c|c|c|c|c|}
\hline & $p, p^{\prime}-\mathrm{DDE}$ & $p, p^{\prime}-\mathrm{DDT}$ & HCB & $r-\mathrm{HCH}$ \\
\hline $\mathrm{ER} \alpha$ agonistic activity REC20 (mol/L) & $>1.0 \times 10^{-4}$ & $5.1 \times 10^{-5}$ & - & - \\
\hline $\mathrm{ER} \alpha$ antagonistic activity REC20 (mol/L) & - & - & - & $2.0 \times 10^{-5}$ \\
\hline AR agonistic activity REC20 (mol/L) & - & - & - & - \\
\hline AR antagonistic activity RIC20 (mol/L) & $3.1 \times 10^{-5}$ & - & $1.7 \times 10^{-6}$ & $1.3 \times 10^{-6}$ \\
\hline PR agonistic activity REC20 (mol/L) & - & - & - & - \\
\hline PR antagonistic activity RIC20 (mol/L) & $2.2 \times 10^{-8}$ & $8.6 \times 10^{-5}$ & - & $4.6 \times 10^{-7}$ \\
\hline ERR $\gamma$ antagonistic activity RIC20 (mol/L) & - & - & $7.7 \times 10^{-5}$ & $>1.0 \times 10^{-4}$ \\
\hline
\end{tabular}

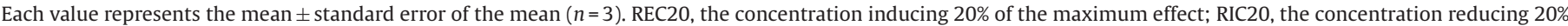
of the maximum effect; $p, p^{\prime}$-DDE, $p, p^{\prime}$-dichlorodiphenylethane; $p, p^{\prime}$-DDT, $p$, $p^{\prime}$-dichlorodiphenyltrichloroethane; HCB, hexachlorobenzen; $r$-HCH, $r$-hexachlorocyclohexane. - , No response.

of RU486, a known PR antagonist was tested with progesterone $\left(1 \times 10^{-9} \mathrm{~mol} / \mathrm{L}\right)$, and the RIC50 value of RU486 was $6.6 \times 10^{-6} \mathrm{~mol} / \mathrm{L}$ (Fig. 2B). 4-OHT, which is an ERR $\gamma$ antagonist, dose-dependently inhibited the high constitutive $\beta$-galactosidase expression with an RIC50 of $7.9 \times 10^{-6} \mathrm{~mol} / \mathrm{L}$ (Fig. $2 \mathrm{C}$ ).

In the present assay using the AR-GRIP1 constructed yeast, the REC50 value of DHT was $1.3 \times 10^{-8} \mathrm{~mol} / \mathrm{L}$, which suggests that the sensitivity of the AR-GRIP1 yeast assay seems to be similar with the previous described by Sohoni and Sumpter (1998) using in vitro yeast-based assays. Furthermore, Ohta et al. (2008) detected the RIC50 value of hydroxyflutamide based on NIH3T3 cell line which was similar to our result. The REC50 value of progesterone $\left(5 \times 10^{-10} \mathrm{~mol} / \mathrm{L}\right)$ is in agreement with that previously obtained by Death et al. (2004). Furthermore, the observation that 4-OHT deactivated ERR $\gamma$ (RIC50 value of $7.9 \times 10^{-6} \mathrm{~mol} / \mathrm{L}$ ) which is consistent with the report that basal activity of ERR $\gamma$ was reduced by as much as $70 \%$ when exposed to $1.0 \times 10^{-5} \mathrm{~mol} / \mathrm{L} 4-\mathrm{OHT}$ (Takayanagi et al., 2006). The two-hybrid ER $\alpha$ yeast used here has previously been demonstrated to have high sensitivity to a range of known estrogen agonists and antagonists, making it a useful screening tool for (anti-)estrogenic activity of uncharacterised chemicals (Li et al., 2008).

\subsection{Gene expression modulation via the $E R \alpha$}

To study ER $\alpha$ agonistic activity, two-hybrid ER $\alpha$ yeast were tested in the presence of increasing concentrations $\left(1 \times 10^{-9}\right.$ to $1 \times 10^{-4} \mathrm{~mol} / \mathrm{L}$ ) of $p, p^{\prime}$-DDE, $p, p^{\prime}$-DDT, HCB and $r$-HCH. $p, p^{\prime}$-DDT was found to be a potent $\mathrm{ER} \alpha$ agonist that significantly induced

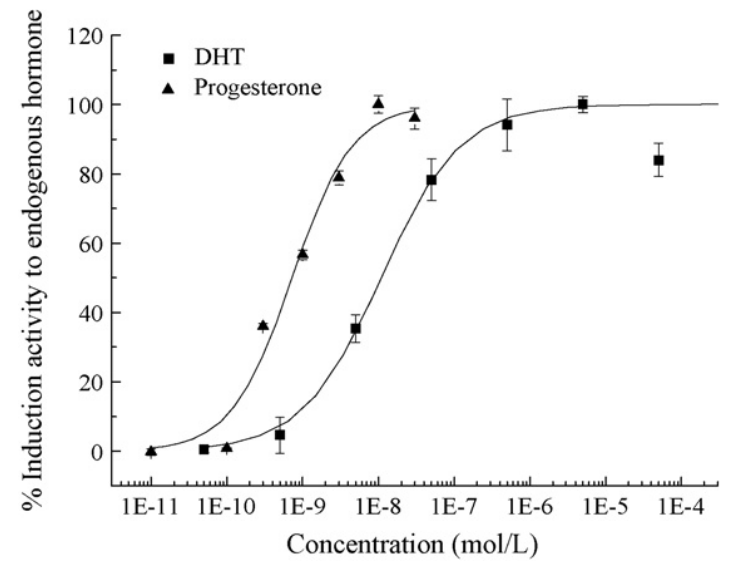

Fig. 1. Typical dose-response relationships induced by dihydrotestosterone(DHT) in yeast strain AR-GRIP1 and progesterone in yeast strain PR. The chemical's agonistic activity is represented as the percent induction activity relative to the maximum induced by endogenous hormone, DHT or progesterone. Values are presented as the average \pm standard error $(n=3)$. the $\beta$-galactosidase activity at concentration of $1 \times 10^{-6} \mathrm{~mol} / \mathrm{L}$ and greater (Fig. 3A). The RIC20 value of $p, p^{\prime}$-DDT was $5.1 \times 10^{-5} \mathrm{~mol} / \mathrm{L}$. While $p, p^{\prime}$-DDE was also potent agonist with 9.3\% ER $\alpha$-binding potency of $E_{2}$ at concentration of $1 \times 10^{-4} \mathrm{~mol} / \mathrm{L}$. The REC20 value of $p, p^{\prime}$-DDE could not be calculated.

When the test chemicals were co-administered with $2 \times 10^{-10} \mathrm{~mol} / \mathrm{L}$ of $\mathrm{E}_{2}$, which was shown to induce sub-maximal
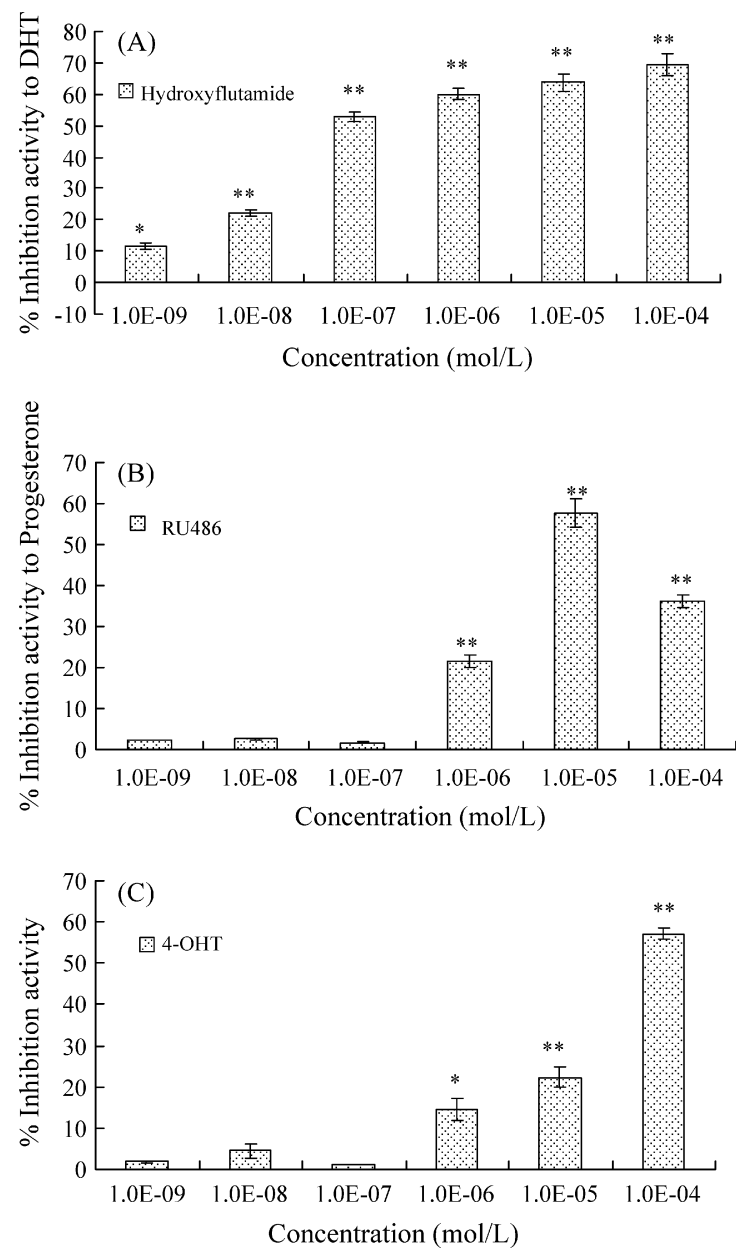

Fig. 2. (A) Inhibition of dihydrotestosterone (DHT)-sensitive $\beta$-galactosidase activity by hydroxyflutamide in yeast strain AR-GRIP1. (B) Inhibition of progesteronesensitive $\beta$-galactosidase activity by RU486 in yeast strain PR. (C) Inhibition of high constitutive $\beta$-galactosidase activity by 4-hydroxytamoxifen (4-OHT) in yeast strain ERR $\gamma$-GRIP1. The chemical's antagonistic activity is represented as the percent inhibition relative to that induced by endogenous hormone $\left(5 \times 10^{-8} \mathrm{~mol} / \mathrm{L}\right.$ DHT or $1 \times 10^{-9} \mathrm{~mol} / \mathrm{L}$ progesterone) in yeast strain AR-GRIP1 and PR or to the high constitutive activity in yeast strain ERR $\gamma$-GRIP1. ${ }^{*} p<0.05,{ }^{* *} p<0.01$ represents a significant decrease in $\beta$-galactosidase activity in the presence of antagonist. Values are presented as the average \pm standard error $(n=3)$. 

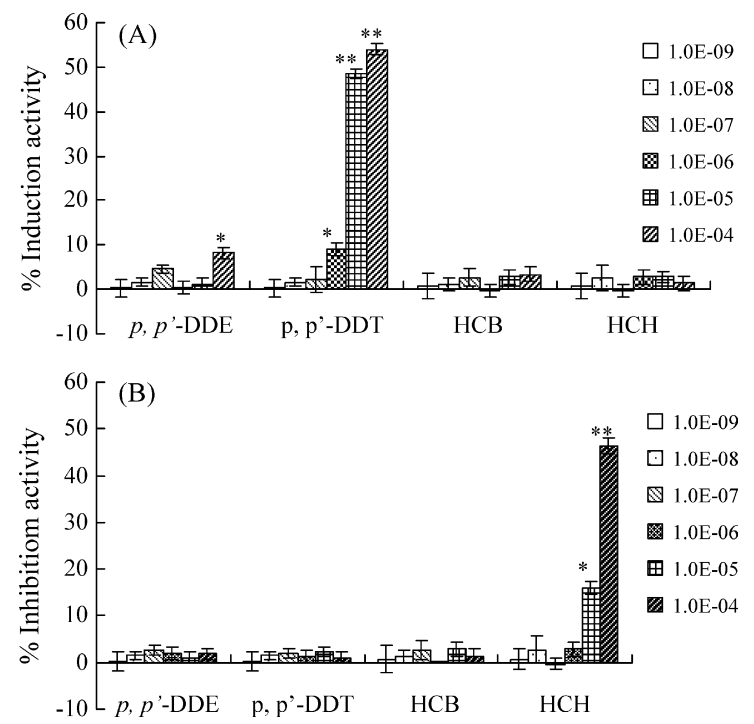

Fig. 3. (A) Estrogen receptor $\alpha(E R \alpha)$ agonistic activity of test chemicals determined by the yeast strain ER $\alpha$-GRIP1. (B) ER $\alpha$ antagonistic activity of test chemicals determined by the yeast strain ER $\alpha$-GRIP1. The chemical's (anti-)agonistic activity is represented as the percent inhibition or induction activity relative to the maximum induced by $17 \beta$-estradiol $\left(\mathrm{E}_{2}, 2 \times 10^{-10} \mathrm{~mol} / \mathrm{L}\right) .{ }^{*} p<0.05$, ${ }^{* *} p<0.01$ represents a significant increase or decrease in $\beta$-galactosidase activity. Values are presented as the average \pm standard error $(n=3) . p, p^{\prime}-\mathrm{DDE}=p, p^{\prime}$-dichlorodiphenylethane, $p, p^{\prime}-\mathrm{DDT}=p, p^{\prime}$ - dichlorodiphenyltrichloroethane; $\mathrm{HCB}$, hexachlorobenzen; $r-\mathrm{HCH}$, $r$-hexachlorocyclohexane.

$\beta$-galactosidase expression, some of them suppressed the $\beta$-galactosidase activity (Fig. 3B). The inhibition by $r-\mathrm{HCH}$ demonstrated a dose-effect relationship. The RIC20 value of $r-\mathrm{HCH}$ was $2.0 \times 10^{-5} \mathrm{~mol} / \mathrm{L}$.

The test chemicals were also demonstrated that they did not affect the viability and proliferation of yeast cell, alone or with $2 \times 10^{-10} \mathrm{~mol} / \mathrm{L} \mathrm{E}_{2}$ assay (data not shown). This indicates that no cytotoxic effect existed in the tested concentration range.

Recently, Nishihara et al. (2000) used a yeast two-hybrid assay system to test 517 chemicals including some pesticides as potential agonists to the rat ER $\alpha$. They found that $p, p^{\prime}-\mathrm{DDE}$ and $p, p^{\prime}$-DDT acted as estrogens with RIC10 $>1 \times 10^{-4} \mathrm{~mol} / \mathrm{L}$ and $>3 \times 10^{-4} \mathrm{~mol} / \mathrm{L}$. However, in the present study, $p, p^{\prime}$-DDT induced the activity of human ER $\alpha$ when its concentration increased to $10^{-6} \mathrm{~mol} / \mathrm{L}$. Such differences are common in reporter gene assays. Oien et al. (1997) reported that $p, p^{\prime}$-DDT and $o, p^{\prime}$-DDT were able to bind specifically to the human ER tested by competitive binding assays. In contrast, only $o, p^{\prime}$-DDT, but not $p, p^{\prime}$-DDT, bound to the rat ER. So, the different results may be attributed to different types of ERs, which underlines the need to study the interaction of xenobiotics with human nuclear receptors.

The data shown here suggests that $r-\mathrm{HCH}$ was able to interact with significant affinity with $\mathrm{ER} \alpha$ showing antagonistic activity. Whereas few results concerning anti-estrogenic activity of $r-\mathrm{HCH}$ have been reported previously, Chadwick et al. (1988) proposed that $r-\mathrm{HCH}$ may be anti-estrogenic rather than estrogenic when tested in female rats, which supports our results.

\subsection{Gene expression modulation via the $A R$}

Our reporter assay system showed none of the test compounds caused any AR transactivation (Fig. 4A), however, p,p'-DDE, HCB and $r-\mathrm{HCH}$, were found to be AR antagonists (Fig. 4B). The RIC20 values of $p, p^{\prime}$-DDE, $\mathrm{HCB}$ and $r$ - $\mathrm{HCH}$ were $3.1 \times 10^{-5}, 1.7 \times 10^{-6}$ and $1.3 \times 10^{-6} \mathrm{~mol} / \mathrm{L}$, respectively (Table 1 ). The order of the antiandrogenic activities was $r-\mathrm{HCH}>\mathrm{HCB}>p, p^{\prime}$-DDE.
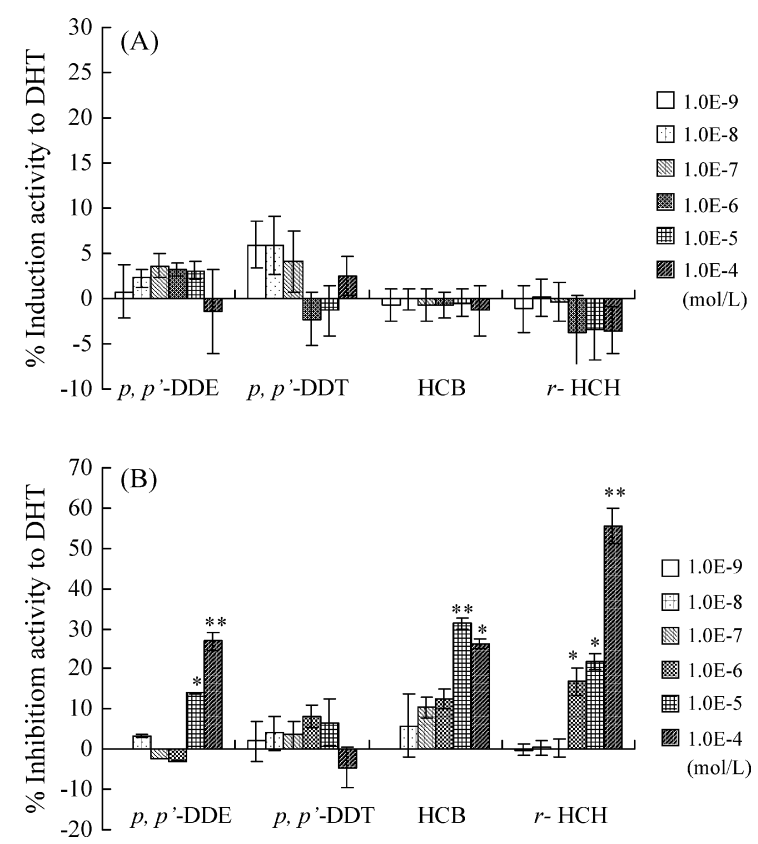

Fig. 4. (A) Androgen receptor (AR) agonistic activity of test chemicals determined by the yeast strain AR-GRIP1. (B) AR antagonistic activity of test chemicals determined by the yeast strain AR-GRIP1. The chemical's (anti-)agonistic activity is represented as the percent inhibition or induction activity relative to the maximum induced by dihydrotestosterone (DHT, $5 \times 10^{-8} \mathrm{~mol} / \mathrm{L}$ ). ${ }^{*} p<0.05$, ${ }^{* *} p<0.01$ represents a significant decrease in $\beta$-galactosidase activity in the presence of antagonist. Values are presented as the average \pm standard error $(n=3) . p, p^{\prime}-\mathrm{DDE}=p, p^{\prime}$-dichlorodiphenylethane, $p, p^{\prime}-\mathrm{DDT}=p, p^{\prime}-$ dichlorodiphenyltrichloroethane; $\mathrm{HCB}$, hexachlorobenzen; $r$ - $\mathrm{HCH}, r$-hexachlorocyclohexane.

In the present study, we found that $p, p^{\prime}$-DDE was not an AR agonist, but was an AR antagonist. In previous studies, $p, p$ '-DDE has been demonstrated to have AR-mediated anti-androgenic activities both in vitro and in vivo (Gray et al., 1994). Xu et al. (2005) also reported the absence of an AR agonistic effect of $p, p^{\prime}$-DDE, but found that $p, p^{\prime}$-DDE was an effective inhibitor of androgen-induced AR transcriptional activity. The AR antagonistic activities of HCB have been investigated but the data are contradictory. Ralph et al. (2003) reported that $\mathrm{HCB}\left(>1 \times 10^{-5} \mathrm{~mol} / \mathrm{L}\right)$ was an anti-androgen. However, Tamura et al. (2006) reported that HCB was not an androgen antagonist. In our study, HCB exhibited stronger anti-androgenic activities (RIC20 of $1.7 \times 10^{-6} \mathrm{~mol} / \mathrm{L}$ ) than did p,p'-DDE. In addition, the RIC20 value of $1.3 \times 10^{-6} \mathrm{~mol} / \mathrm{L}$ measured for $r-\mathrm{HCH}$ was consistent with the values reported by Tamura et al. (2006).

These results suggest that $p, p^{\prime}-\mathrm{DDE}, \mathrm{HCB}$ and $r$-HCH act as AR antagonists. Once bound to AR, the androgen antagonists are transported into the nucleus and prevent endogenous androgens from regulating androgen-dependent transcription. The AR-compound interaction may be crucial contributor to adverse effects on male reproductive system. Exposure of fish to anti-androgens like OCPs has been associated with gonadal changes (induction of intersex), reduced spermatogenesis, demasculinization, and reduced sperm counts (Kiparissis et al., 2003).

\subsection{Gene expression modulation via the progesterone receptor (PR)}

The potential activity of OCPs via PR was investigated using recombined PR yeast, in which none of the above-mentioned compounds showed agonistic activity (Fig. 5A). Antagonist activity was determined by co-incubation with $1 \times 10^{-9} \mathrm{~mol} / \mathrm{L}$ progesterone. In the results, $p, p$ '-DDE and $r$-HCH showed strong antagonistic effects 

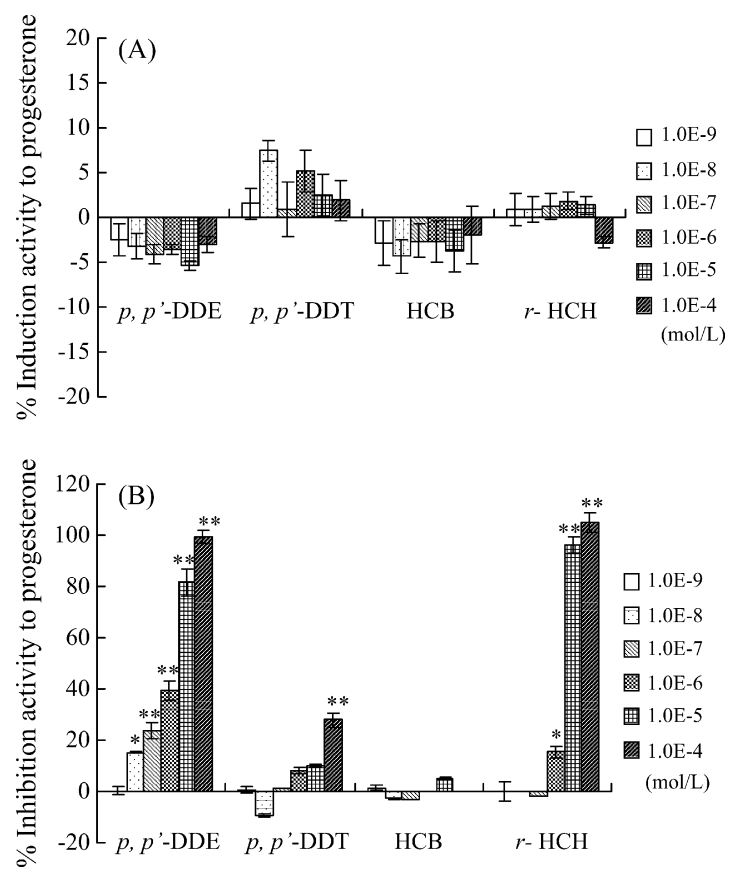

Fig. 5. (A) Progesterone receptor (PR) agonistic activity of test chemicals determined by the yeast strain PR. (B) PR antagonistic activity of test chemicals determined by the yeast strain PR. The chemical's (anti-)agonistic activity is represented as the percent inhibition or induction activity relative to the maximum induced by progesterone $\left(1 \times 10^{-9} \mathrm{~mol} / \mathrm{L}\right) .{ }^{*} p<0.05,{ }^{* *} p<0.01$ represents a significant decrease in $\beta$-galactosidase activity in the presence of antagonist. Values are presented as the average \pm standard error $(n=3) . p, p^{\prime}-\mathrm{DDE}=p, p^{\prime}$-dichlorodiphenylethane; $p, p^{\prime}$-DDT, $p, p$ '- dichlorodiphenyltrichloroethane; $\mathrm{HCB}$, hexachlorobenzen; $r-\mathrm{HCH}, r$ hexachlorocyclohexane.

with the RIC20 value of $2.2 \times 10^{-8}$ and $4.6 \times 10^{-7} \mathrm{~mol} / \mathrm{L}$, respectively (Fig. 5B, Table 1 ). At $1.0 \times 10^{-5} \mathrm{~mol} / \mathrm{L}$ and greater, $p, p^{\prime}$-DDT decreased the $\beta$-galactosidase expression obviously, then the RIC20 value for $p, p^{\prime}$-DDT was determined to be $8.6 \times 10^{-5} \mathrm{~mol} / \mathrm{L}$. In contrast, HCB was not an antagonist of the PR.

Our results demonstrate that both $p, p^{\prime}$-DDT and $p, p^{\prime}$-DDE are antagonists. The effect of DDT and its metabolites on the PR has previously been investigated and that study confirmed that $o, p^{\prime}$-DDT and its metabolites $p, p^{\prime}$-DDT, $o, p^{\prime}$-DDE, $p, p^{\prime}$-DDE, and $p, p^{\prime}$-dichlorodiphenyl acetic acid inhibited progesterone-induced reporter gene activity in a dose-dependent manner (Klotz et al., 1997).

The fact that $r$ - $\mathrm{HCH}$ inhibited PR-controlled $\beta$-galactosidase expression suggests that it is a PR antagonist, which had not been reported previously. The ability of $r-\mathrm{HCH}$ to inhibit progesteroneinduced gene transcription in the yeast may reflect the ability of $r$-HCH to compete with progesterone for binding to hPR. Recently several studies have shown that functional interactions between estrogen and progesterone are fundamental to maintaining some physiological processes and suggested that progestins can oppose the effects of estrogens in some systems (Kraus et al., 1995). Thus, research on the agonistic and antagonistic activities of the chemicals provide endocrine disrupting mechanistic insight in the level at which these compounds are likely to disturb the PR system and induce/inhibit PR mediated cellular responses.

\subsection{Modulation of gene expression via the estrogen-related receptor $\gamma(E R R \gamma)$}

None of the chemicals increased $\beta$-galactosidase expression compared with negative control (DMSO, data not shown). However, HCB was a strong ERR $\gamma$ antagonist with RIC20 value of
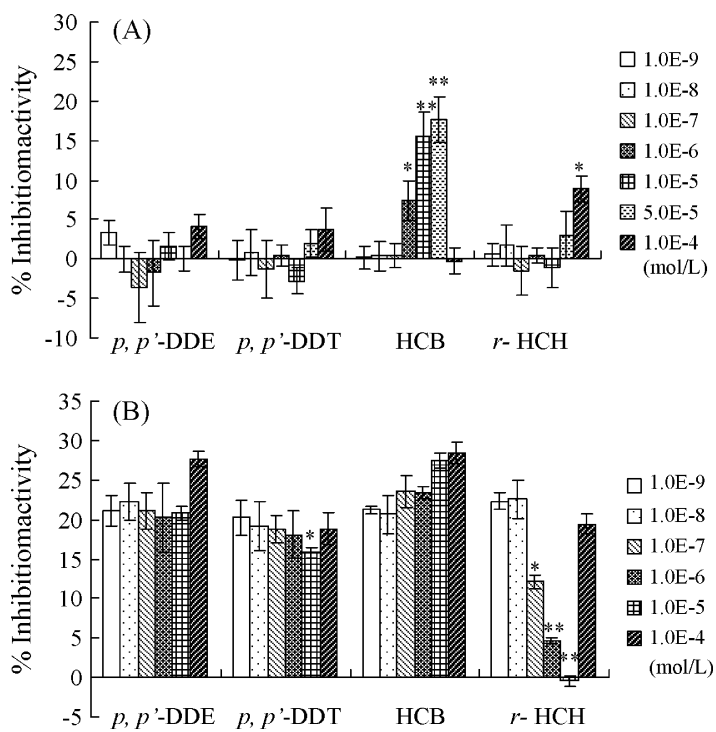

Fig. 6. (A) Estrogen-related receptor $\gamma(E R R \gamma)$ antagonistic activity of test chemicals determined by the yeast strain ERR $\gamma$-GRIP1. (B) Effect of test chemicals on the inverse agonist activity of 4-hydroxytamoxifen (4-OHT) in yeast strain ERR $\gamma$ GRIP1.The chemical's antagonistic activity is represented as the percent inhibition activity relative to the high constitutive activity in yeast strain ERR $\gamma$-GRIP1. ${ }^{*} p<0.05$, ${ }^{* *} p<0.01$ represents a significant decrease in $\beta$-galactosidase activity in the presence of antagonist. Values are presented as the average \pm standard error $(n=3) . p, p^{\prime}-\mathrm{DDE}$, $p, p^{\prime}$-dichlorodiphenylethane; $p, p^{\prime}$-DDT, $p, p^{\prime}$ - dichlorodiphenyltrichloroethane; HCB, hexachlorobenzen; $r$-HCH, $r$-hexachlorocyclohexane.

$7.7 \times 10^{-5} \mathrm{~mol} / \mathrm{L}$ (Fig. $6 \mathrm{~A}$ ). The inhibition effect of $r$-HCH was so weak that the RIC20 value could not be determined (Table 1 ).

Then $1.0 \times 10^{-5} \mathrm{~mol} / \mathrm{L} 4-\mathrm{OHT}$, which inhibited about $20 \%$ ERR $\gamma$ of the constitutive activity, was chosen as standard antagonist to test the inhibitory effect of OCPs on the inverse agonist activity of 4-OHT. The result showed that 4-OHT's antagonistic activity was suppressed by $r$-HCH (Fig. 6B) and almost all activity induced by 4-OHT was reversed by $r$ - $\mathrm{HCH}$ at $1.0 \times 10^{-5} \mathrm{~mol} / \mathrm{L}$. In comparison, $p, p^{\prime}-\mathrm{DDE}, p, p^{\prime}$-DDT and HCB did not reverse the inverse activity of 4-OHT.

In the present study, HCB was reported for the first time to be a strong antagonist for ERR $\gamma$. Two other OCPs, toxaphene and chlordane, have been reported to behave as ligands of ERR $\alpha-1$ showing antagonistic activities in the yeast one-hybrid assay (Yang and Chen, 1999). Considering the fact that ERR can bind to several functional EREs, these results suggest that the antagonistic action against ERR may be one of the endocrine disrupting effects of these OCPs.

It has been confirmed that $r$ - $\mathrm{HCH}$ can modulate female reproductive development due to its estrogenic activity which might be association with the interaction with ER $\beta$ (Maranghi et al., 2007). In the present study, it was found that $r$ - $\mathrm{HCH}$ could interact with ERR $\gamma$ and showed a strong effect on the inverse agonist activity of 4-OHT. It has also been shown that BPA could antagonize the inhibition activity of 4-OHT and such potential functional crosstalk between the ERR and ER systems might explain some of the estrogenic activities of BPA (Takayanagi et al., 2006). Thus, similar to BPA, the interaction with the ERR $\gamma$ was a possible mechanism for the estrogenic activity observed for $r-\mathrm{HCH}$.

\subsection{Toxicity profiling}

All the results in this study suggested that $p, p^{\prime}$-DDE acted as an $\mathrm{ER} \alpha$ agonist as well as an antagonist of AR and PR, but the abilities to interact with $\mathrm{ER} \alpha, \mathrm{AR}$ and PR were significantly different. $p, p^{\prime}$-DDE exhibited an obvious estrogenic activity at the highest 
concentration used in our studies, $1.0 \times 10^{-4} \mathrm{~mol} / \mathrm{L}$. However, the lowest concentration to observe the anti-androgenic and antiprogesteronic activity of $p, p^{\prime}$-DDE were detected at $1.0 \times 10^{-5} \mathrm{~mol} / \mathrm{L}$ and $1.0 \times 10^{-8} \mathrm{~mol} / \mathrm{L}$, respectively. The RIC20 values of $p, p^{\prime}$-DDE for AR and PR inhibition were $3.1 \times 10^{-5} \mathrm{~mol} / \mathrm{L}$ and $2.2 \times 10^{-8} \mathrm{~mol} / \mathrm{L}$, respectively. Endocrine disrupters are widely known for their estrogenic and androgenic effects by binding to ER or AR. But, the mechanisms of action of endocrine disrupters are actually complicated. For $p, p^{\prime}$-DDE, it was found that the most obvious interrupting effect was inhibiting the gene expression via the PR at $1.0 \times 10^{-8} \mathrm{~mol} / \mathrm{L}$. Interestingly, similar results obtained with $p, p^{\prime}-$ DDT which may interact with ER $\alpha$ and PR at the concentration level of $10^{-5} \mathrm{~mol} / \mathrm{L}$ showing strong estrogenic and anti-progesteronic activity. Therefore, although disruption of the progesterone activity was rarely addressed in the past, in contrast to estrogenic and anti-androgenic activities, it could well contribute to trigger a wide range of hormonal and/or anti-hormonal effects in vivo (MolinaMolina et al., 2006).

Besides the antagonistic effect on AR, HCB also showed interaction with ERR $\gamma$ as an antagonist. The RIC20 values of HCB for AR and ERR $\gamma$ inhibition activity were $1.7 \times 10^{-6} \mathrm{~mol} / \mathrm{L}$ and $7.7 \times 10^{-5} \mathrm{~mol} / \mathrm{L}$, respectively. Furthermore, we confirmed that $r-\mathrm{HCH}$, which up to now had been reported to possess only estrogenic activity and anti-androgenic activity, was a potent PR antagonist as well. Furthermore, $r$-HCH was also found to be an inhibitor that reversed the antagonistic effect induced by 4-OHT at the level of ERR $\gamma$. These results suggest that the tested chemicals might exhibit multiple hormonal activities, which renders difficult interpretation of their mechanism of action. Although the potency of these OCPs to behave as a hormone agonists or antagonists is low compared to the natural ligands, their ability to act via more than one mechanism might contribute to their biological effects in the intact organism, because the final response will likely be determined by the interactions of all the implicated pathways (Molina-Molina et al., 2006). Thus, for a detailed risk assessment of OCPs concerning endocrine disruption in humans and animals, more data are needed, especially in vivo data.

\section{Conflict of interest statement}

I declare no conflict of interest.

\section{Acknowledgements}

This study was supported by National Natural Science Foundation of China (20677075), the National Basic Research Program of China (2003CB415005), and Natural Science Foundation of Beijing Municipality (8061004).

\section{References}

Chadwick, R.W., Cooper, R.L., Chang, J., Rehnberg, G.L., McElroy, W.K., 1988. Possible antiestrogenic activity of lindane in female rats. J. Biochem. Toxicol. 3, 147158.

Chen, C.W., Hurd, C., Vorojeikina, D.P., Arnold, S.F., Notides, A.C., 1997. Trascriptional activation of the human estrogen receptor by DDT isomers and metabolites in yeast and MCF-7 cells. Biochem. Pharmacol. 53, 1161-1172.

Colborn, T., vom Saal, F.S., Soto, A.M., 1993. Developmental effects of endocrinedisrupting chemicals in wildlife and humans. Environ. Health Perspect. 101, 378-384.

Death, A.K., Mcgrath, K.C.Y., Kazlauskas, R., Handelsman, D.J., 2004. Tetrahydrogestrinone Is a Potent Androgen and Progestin. J. Clin. Endocr. Metab. 89 (5), 2498-2500.

Doesburg, P., Kuil, C.W., Berrevoets, C.A., Steketee, K., Faber, P.W., Mulder, E., Brinkmann, A.O., Trapman, J., 1997. Functional in vivo interaction between the amino-terminal, transactivation domain and the ligand binding domain of the androgen receptor. Biochemistry 36, 1052-1064.

Gaido, K.W., Leonard, L.S., Lovell, S., Gould, J.C., Babai, D., Portier, C.J., 1997. Evaluation of chemicals with endocrine modulating activity in a yeast-based steroid hormone receptor gene transcription assay. Toxicol. Appl. Pharmacol. 143, 205212.

Graham, J.D., Clarke, C.L., 1997. Physiological action of progesterone in target tissues Endocr. Rev. 18, 502-519.

Gray, L.E., Ostby, J.S., Kelce, W.R., 1994. Developmental effects of an environmenta antiandrogen: the fungicide vinclozolin alters sex differentiation of the male rat. Toxicol. Appl. Pharmacol. 129, 46-52.

Hong, H., Kohli, K., Garabedian, M.J., Stallcup, M.R., 1997. GRIP1, a transcriptional coactivator for the AF-2 transactivation domain of steroid, thyroid, retinoid, and vitamin D receptors. Mol. Cell. Biol 17, 2735-2744.

Hong, H., Yang, L., Stallcup, M.R., 1999. Hormone-independent transcriptional activation and coactivator binding by Novel Orphan Nuclear Receptor ERR3. J. Biol. Chem. 274 (32), 22618-22626.

Horard, B., Vanacker, J.M., 2003. Estrogen receptor-related receptors: orphan receptors desperately seeking a ligand. J. Mol. Endocrinol. 31, 349-357.

Johnson, W.E., 1999. Native Sport Fish Enhancement. III. Effects of pesticide contamination on reproductive hormone concentrations in sport fish. Report to the Florida Fish and Wildlife Conservation Commission, Eustis, FL.

Kelce, W.R., Wilson, E.M., 1997. Environmental antiandrogens: developmental effects, molecular mechanisms, and clinical implications. J. Mol. Med. 75, 198-207.

Kiparissis, Y., Metcalfe, T.L., Balch, G.C., Metcalfe, C.D., 2003. Effects of antiandrogens, vinclozolin and cyproterone acetate on gonadal development in the Japanese medaka (Oryzias latipes). Aquat. Toxicol. 63, 391-403.

Klotz, D.M., Ladlie, B.L., Vonier, P.M., McLachlan, J.A., Arnold, S.F., 1997. o,p'-DDT and its metabolites inhibit progesterone-dependent responses in yeast and human cells. Mol. Cell Endocrinol. 129 (1), 63-71.

Kraus, W.L., Weis, K.E., Katzenellenbogen, B.S., 1995. Inhibitory cross-talk between steroid hormone receptors: differential targeting of estrogen receptor in the repression of its transcriptional activity by agonist- and antagonist-occupied progestin receptors. Mol. Cell Biol. 15 (4), 1847-1857.

Kristensen, T., Baatrup, E., Bayley, M., 2006. p,p'-DDE fails to reduce the competitive reproductive fitness in Nigerian male guppies. Ecotoxicol. Environ. Saf. 63 (1) 148-157.

Li, J., Ma, M., Rao, K.F., Wang, Z.J., 2008. Construction the recombinant human estrogen receptor (hER) gene yeast using two-hybrid yeast technique. Asian J Ecotoxicol. 3 (1), 21-26.

Ma, M., Li, J., Wang, Z., 2005. Assessing the detoxication efficiencies of wastewater treatment processes using a battery of bioassays/biomarkers. Arch. Environ. Contam. Toxicol. 49, 480-487.

Maranghi, F., Rescia, M., Macrì, C., Consiglio, E.D., Angelis, G.D., Testai, E., Farini, D. Felici, M.D., Lorenzetti, S., Mantovani, A., 2007. Lindane may modulate the female reproductive development through the interaction with ER-beta: an in vivo-in vitro approach. Chem. Biol. Interact. 169, 1-14.

Meisel, R.L., Sachs, B.D., 1994. The physiology of male sexual behavior. In: Knobil, E., Neill, J. (Eds.), The Physiology of Reproduction, 2nd ed. Raven Press, New York, pp. 3-105.

Molina-Molina, J.M., Hillenweck, A., Jouanin, I., Zalko, D., Cravedi, J.P., Fernández, M.F., Pillon, A., Nicolas, J.C., Olea, N., Balaguer, P., 2006. Steroid receptor profiling of vinclozolin and its primary metabolites. Toxicol. Appl. Pharmacol. 216, 4454.

Nishihara, T., Nishikawa, J., Kanayama, T., Dakeyama, F., Saito, K., Imagawa, M. Takatori, S., Kitagawa, Y., Hori, S., Utsumic, H., 2000. Estrogenic activities of 517 chemicals by yeast two-hybrid assay. J. Health Sci. 46 (4), 282296.

Nuclear Receptors Nomenclature Committee, 1999. A unified nomenclature system for the nuclear receptor superfamily. Cell 97, pp. 1611-1663.

Ohta, K., Goto, T., Fijii, S., Suzuki, T., Ohta, S., Endo, Y., 2008. Design and synthesis of carborane-containing androgen receptor (AR) antagonist bearing a pyridine ring. Bioorg. Med. Chem. 16, 8022-8028.

Oien, C.W., Hurd, C., Vorojeikina, D.P., Amold, S.F., Notides, A.C., 1997. Transcriptional activation of the human estrogen receptor by DDT isomers and metabolites in yeast and MCF-7 cells. Biochem. Pharmacol. 53 (8), 11611172.

Ralph, J.L., Orgebin-Crist, M.C., Lareyre, J.J., Nelson, C.C., 2003. Disruption of Androgen Regulation in the Prostate by the Environmental Contaminant Hexachlorobenzene. Environ. Health Perspect. 111 (4), 461-466.

Rehmann, R.K., Schramm, K.W., Kettrup, A.A., 1999. Applicability of a yeast oestrogen screen for the detection of oestrogen-like activities in environmental samples. Chemophere 38, 3303-3312.

Sohoni, P., Sumpter, J.P., 1998. Several environmental oestrogens are also antiandrogens. J. Endocrinol. 158, 327-339.

Sonnenschein, C., Soto, A.M., 1998. An updated review of environmental estrogen and androgen mimics and antagonists. J. Steroid Biochem. Mol. Biol. 65, 143150.

Soto, A.M., Sonnenschein, C., Chung, K.L., Fernandez, M.F., Olea, N., Serrano, F.O., 1995. The E-SCREEN assay as a tool to identify estrogens: an update on estrogenic environmental pollutants. Environ. Health Perspect. 103, 113122.

Takayanagi, S., Tokunaga, T., Liu, X., Okada, H., Matsushima, A., Shimohigashi, Y. 2006. Endocrine disruptor bisphenol A strongly binds to human estrogenrelated receptor $\gamma(\mathrm{ERR} \gamma)$ with high constitutive activity. Toxicol. Lett. 167, 95-105.

Tamura, H., Ishimoto, Y., Fujikawa, T., Aoyama, H., Yoshikawa, H., Akamatsu, M., 2006 Structural basis for androgen receptor agonists and antagonists: Interaction of 
SPEED 98-listed chemicals and related compounds with the androgen receptor based on an in vitro reporter gene assay and 3D-QSAR. Bioorg. Med. Chem. 14, $7160-7174$

Wang, J., Xie, P., Kettrup, A., Schramm, K.W., 2005. Inhibition of progesterone recepto activity in recombinant yeast by soot from fossil fuel combustion emissions and air particulate materials. Sci. Total Environ. 349, 120-128.
Xu, L.C., Sun, H., Chen, J.F., Bian, Q., Qian, J., Song, L., Wang, X.R., 2005. Evaluation of androgen receptor transcriptional activities of bisphenol A, octylphenol and nonylphenol in vitro. Toxicology 216, 197-203.

Yang, C., Chen, S., 1999. Two organochlorine pesticides, toxaphene and chlordane, are antagonists for estrogen-related receptor alpha-1 orphan receptor. Cancer Res. 59, 4519-4524. 